\title{
Localization of chondromodulin-I at the feto- maternal interface and its inhibitory actions on trophoblast invasion in vitro
}

\author{
Shigenori Miura' ${ }^{1}$ Chisa Shukunami ${ }^{1}$, Kaori Mitsui ${ }^{2}$, Jun Kondo ${ }^{3}$ and Yuji Hiraki ${ }^{*}$
}

\begin{abstract}
Background: Chondromodulin-I (ChM-l) is an anti-angiogenic glycoprotein that is specifically localized at the extracellular matrix of the avascular mesenchyme including cartilage and cardiac valves. In this study, we characterized the expression pattern of ChM-I during early pregnancy in mice in vivo and its effect on invasion of trophoblastic cells into Matrigel in vitro.

Results: Northern blot analysis clearly indicated that ChM-I transcripts were expressed in the pregnant mouse uterus at 6.5-9.5 days post coitum. In situ hybridization and immunohistochemistry revealed that ChM-I was localized to the mature decidua surrounding the matrix metalloproteinase-9 (MMP-9)-expressing trophoblasts. Consistent with this observation, the expression of ChM-I mRNA was induced in decidualizing endometrial stromal cells in vitro, in response to estradiol and progesterone. Recombinant human ChM-I (rhChM-I) markedly inhibited the invasion through Matrigel as well as the chemotactic migration of rat Rcho-1 trophoblast cells in a manner independent of MMP activation.
\end{abstract}

Conclusions: This study demonstrates the inhibitory action of ChM-I on trophoblast migration and invasion, implying the potential role of the ChM-I expression in decidual cells for the regulated tissue remodeling and angiogenesis at feto-maternal interface.

\section{Background}

Chondromodulin-I (ChM-I) is a naturally occurring anti-angiogenic glycoprotein that localizes to the avascular domains of mesenchymal tissues such as cartilage, cardiac valves, and the eye [1-3], where angiogenesis is strictly limited. Using both recombinant and adenovirally expressed ChM-I protein, we have demonstrated that ChM-I inhibits the migration, proliferation, and tube morphogenesis of cultured vascular endothelial cells, and suppresses tumor angiogenesis [4-8]. Moreover, ChM-I-deficient mice show a vascularized phenotype in their aged cardiac valves, which is caused by a loss of anti-angiogenic valvular functions and abnormal vascular invasion [2]. These studies suggest that ChM-I may serve as a matrix component that confers antiangiogenic resistance to specific mesenchymal tissues.

\footnotetext{
* Correspondence: hiraki@frontier.kyoto-u.ac.jp

'Department of Cellular Differentiation, Institute for Frontier Medical

Sciences, Kyoto University, Kyoto 606-8507, Japan Full list of author information is available at the end of the article
}

During mouse skeletal development, expression of $C h M-I$ was dramatically increased in association with cartilage formation. In situ hybridization revealed that the transcripts were detected at the sites of chondrogenesis such as the occipital bone rudiments at 11 days p.c. in mouse embryos. Then the specific expression of ChM-I became apparent in all cartilaginous skeletal elements in the body including the nasal septum, tracheal rings, ribs, and vertebral column [9]. Prior to chondrogenesis, ChM-I transcripts were detected in cardiac valve precursor cells of the heart at 9.5 days post coitum (p.c.) and its expression persisted in cardiac valves in the adult [2].

In the course of our study to explore the sites of ChM-I expression in early stages of development, we carried out northern blot analysis of pregnant mouse uterus and found it to be a prominent expression site at 7.5 day p.c. or later. Then, after detailed analysis, we unexpectedly found that intense (or strong) hybridization signals were detected in maternal tissues such as
Ciomed Central 
decidua rather than embryos at this early stage of pregnancy. In this study, we determined the differentiated mouse decidua as a novel site of ChM-I expression and found that ChM-I transcripts were induced by the decidualization of endometrial stromal cells in vitro. We examined here a possible involvement of ChM-I in angiogenic events and tissue remodeling of decidua by a Matrigel invasion assay in vitro.

\section{Results}

\section{Expression of ChM-I in the decidua during the early implantation period}

In mice, implantation occurs at between 4.5-5.0 days p.c. and triggers the transformation of uterine stroma into the cohesive spongy tissue called decidua. This event accompanies drastic tissue remodeling via the uterine angiogenesis and the invasion of trophoblasts to make feto-maternal connections required for the maintenance of pregnancy. By northern blot analysis, ChM-I transcripts were undetectable in the uterus at 5.5 days p.c. as well as in the non-pregnant mouse uterus (Figure 1A). These transcripts became barely detectable at 6.5 days p.c. and were at their most abundant levels at 7.5 days p.c. The expression levels gradually declined from the onset of placentation (around 8.5 days p.c.) onward. The temporal pattern of ChM-I expression was thus found to be similar to that of Prl8a2 (prolactin family 8, superfamily a, member 2) (Figure 1A), which is expressed in the trophoblasts and the decidua [10]. In contrast, transcripts for TIMP-3 (tissue inhibitor of matrix metalloproteinase-3) and VEGF-A 164 (vascular endothelial growth factor- $\mathrm{A}_{164}$ ), both known angiogenesis-related gene products expressed in the decidua, increased until 7.5 days p.c., and then rapidly disappeared. As shown in Figure 1B, RT-PCR analysis of a pregnant mouse uterus (7.5 days p.c.) indicated that ChM-I expression was strongly detected in the maternal decidua that also expressed Prl8a2, but was marginal in the embryonic tissue that was positive for Brachyury, a marker of the mesoderm [11]. The placenta (13.5 days p.c.), which is formed through the fusion of the decidua, EPC (ectoplacental cone), chorion, and parts of the allantois, was also positive for ChM-I.

In situ hybridization revealed that the ChM-I transcripts were first detected around the EPC, which contains undifferentiated populations of trophoblast, at 6.5 days p.c. (Figure 2A). Interestingly we found that TIMP-3 was strongly expressed in the primary decidua, a mature portion of this structure, and that the localization of TIMP-3 transcripts was complementary to that of ChM-I (Figure 2B). At 7.5 days p.c., the site of ChM-I expression was considerably expanded to the entire primary decidua, whilst TIMP-3 expression was restricted to the thin layer of the primary decidua closer to the implanting embryo.

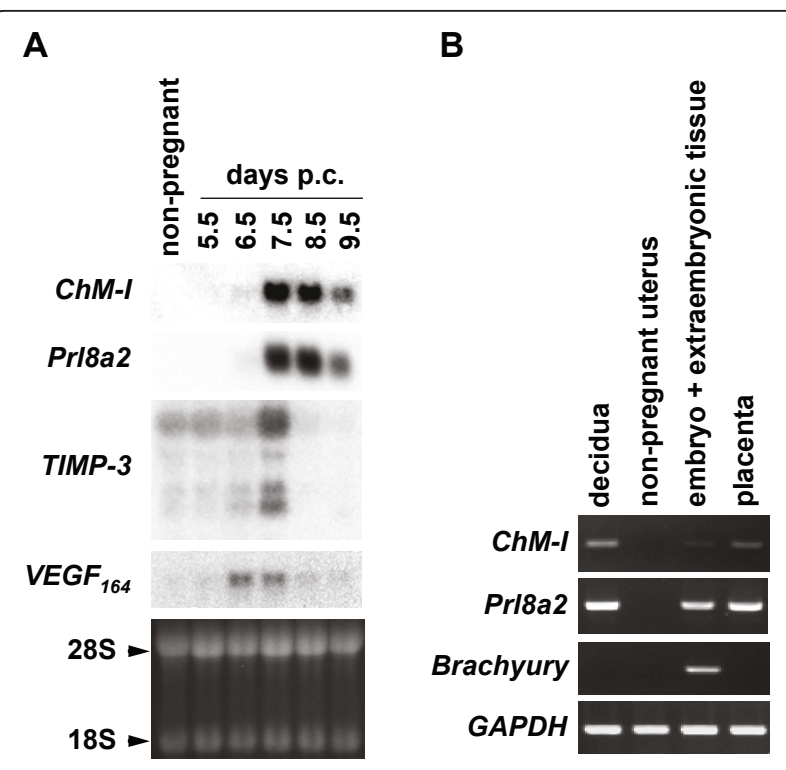

Figure 1 Expression of $\mathrm{ChM}-\mathrm{I}$ in the mouse uterus during early pregnancy. (A) Northern blot analysis of ChM-I mRNA in the pregnant mouse uterus. Total RNA was extracted from pregnant mouse uteri (myometrium + decidua + embryo) and non-pregnant mouse uteri, separated on a denatured agarose gel, and transferred to a nylon membrane. The blots were then hybridized with a radiolabeled probe for ChM-I, Prl8a2, TIMP-3, and VEGF-A 164 , respectively. The equivalent loading of RNA (15 $\mu \mathrm{g} / \mathrm{lane})$ in each lane was verified by ethidium bromide staining. Arrowheads indicate the positions of the $28 \mathrm{~S}$ and $18 \mathrm{~S}$ ribosomal RNAs. (B) Total RNA was extracted from decidua (7.5 days p.c.), non-pregnant mouse uteri (8week-old), embryos (7.5 days p.c., including extraembryonic tissues), and placenta (13.5 days p.c.). The decidual tissues were prepared by the removal of embryos and extraembryonic tissues from whole decidual capsules. One microgram of each total RNA preparation was reverse-transcribed, and the expression of ChM-I and marker genes (Prl8a2, a marker for trophoblasts and decidua; Brachyury, a marker for embryonic tissue) was analyzed by RT-PCR (30 cycles). GAPDH was used as an internal control. The data are representative of three independent experiments.

The expression sites of these angiogenesis inhibitors were found to overlap with that of Prl8a2 (Figure 2I) and the invasive trophoblast giant cells that express a high level of MMP-9 (matrix metalloproteinase-9) and Prl3d1 (prolactin family 3, superfamily d, member 1) (Figures 2D-J) at the margin of the implantation chamber. By 8.5 days p.c., ChM-I transcripts were found to be expressed at a lower level around the EPC, where MMP-9 expressing trophoblast giant cells invade the decidua basalis to form the placenta (data not shown). These dynamic changes in the expression pattern of ChM-I are suggestive of their functional role in regulating the invasion of MMP-9 expressing trophoblasts.

\section{Localization of ChM-I protein in the decidua}

Just after implantation, trophoblasts immediately invade the decidual matrix and form vascular connections with 


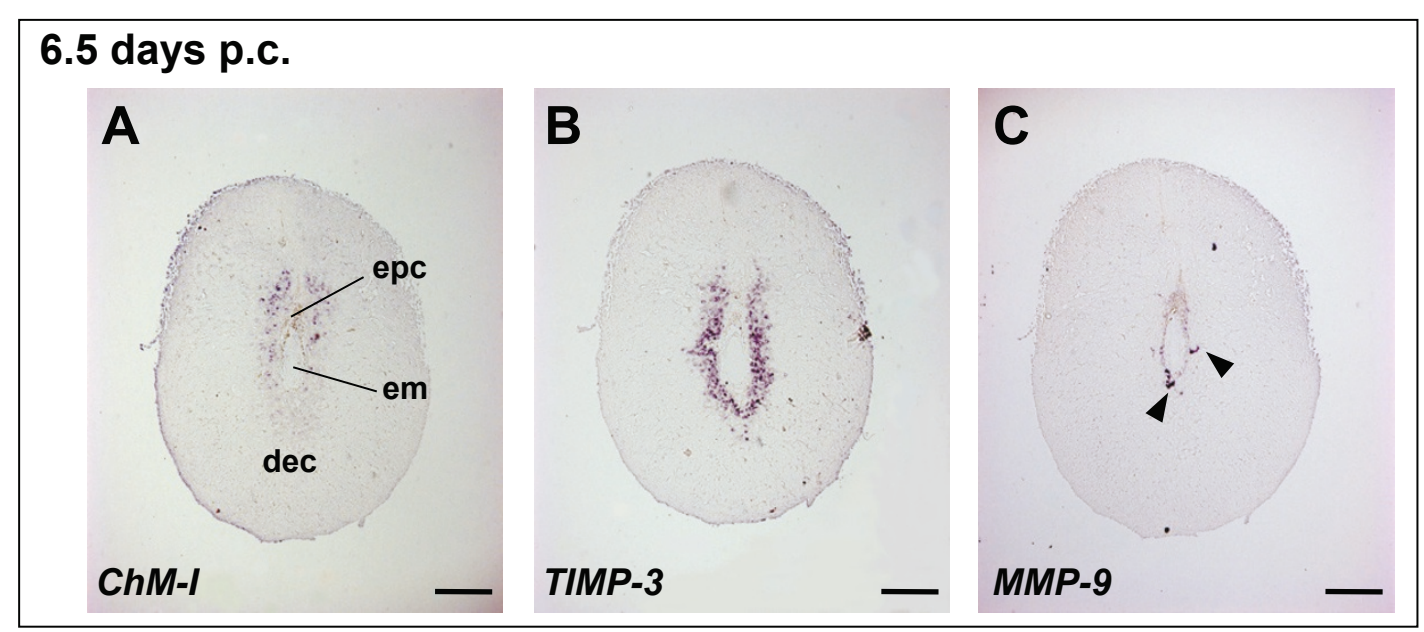

\section{5 days p.c.}
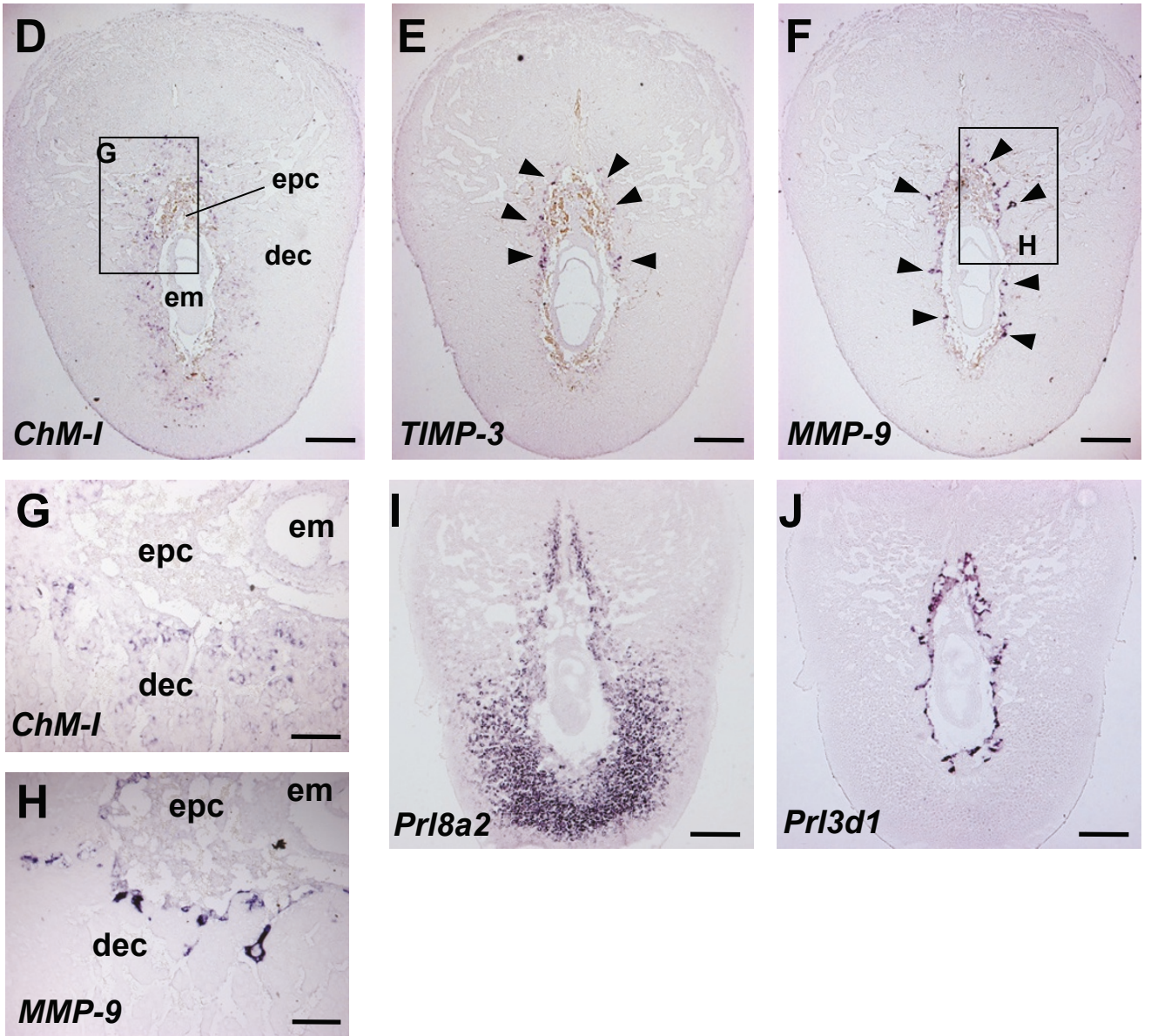

Prl3d1

Figure 2 Localization of ChM-I transcripts in the decidua. Expression of ChM-I ( $A, D$, and G), TIMP-3 (B and E), and MMP-9 (C, F, and H) transcripts analyzed by in situ hybridization using semi-serial sections of 6.5 (A-C) and 7.5 (D-F) days p.c. mouse decidual capsules. Expression of Prl8a2 (I) and Prl3d1 (a marker for trophoblasts; J) transcripts were also examined at 7.5 days p.c. Boxed areas in panels D and F are magnified in panels $\mathrm{G}$ and $\mathrm{H}$, respectively. Note that, at 7.5 days p.c., ChM-I transcripts were broadly detectable in the primary decidua surrounding the implanting embryo and in MMP-9-positive cells (arrowheads in panel C and F), whilst TIMP-3 transcripts (arrowheads in panel E) were marginally detected at the mesometrial side. All images are representative of at least three independent experiments. epc, ectoplacental cone; em, embryo; dec, decidua. Bars in panels A-F and I-J, $300 \mu \mathrm{m}$; bars in panels G-H, $100 \mu \mathrm{m}$. 
the maternal blood supply [12]. We therefore examined the localization of ChM-I protein in the decidua at 7.5 days p.c., comparing it with the distribution of maternal vascular networks and invading trophoblasts (Figure 3). To visualize the invading fetal tissue and the maternal vasculature, transgenic male mice ubiquitously expressing EGFP were mated with wild-type female mice, and the decidual sections were stained with anti-PECAM-1 antibody (Figures 3A and 3B). PECAM-1 immunoreactivity was detected in the whole decidua and was relatively strong in the primary decidua surrounding the EGFP-positive fetal invading cells (Figure 3B). Consistent with its mRNA localization (Figure 2), secreted ChM-I protein was detected in a punctate distribution in the primary decidua, where PECAM-1-positive maternal blood vessels and the invading trophoblasts may strongly interact with each other (Figures $3 \mathrm{C}$ and 3D).

Expression of genes associated with angiogenesis and ECM remodeling in cultured decidual cells and EPCS Tissue remodeling and angiogenesis are two hallmark events that represent active tissue-tissue interactions at

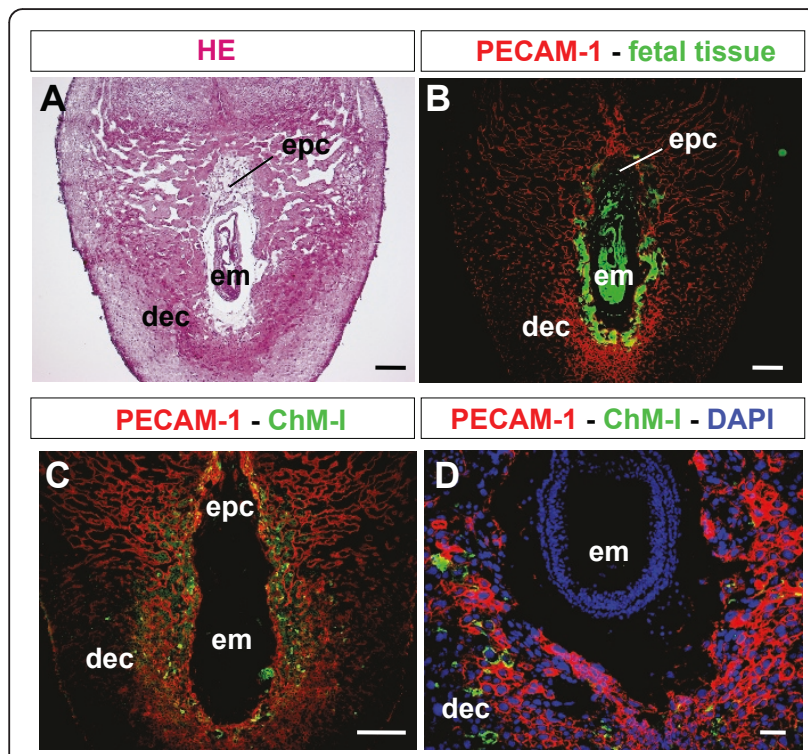

Figure 3 Localization of ChM-I protein in the decidua. (A and B) Visualization of invading fetal tissue through the decidua. Female mice were mated with homozygous EGFP transgenic male mice. At 7.5 days p.c., decidual capsules were dissected from the pregnant mice, fixed, and cryo-sectioned. Semi-serial sections were stained with HE (A) and anti-PECAM-1 antibodies ( $B$, red), respectively. Fetal tissue (green) invading through the maternal decidua was observed under a fluorescence microscope. (C and D) Localization of ChM-I protein and PECAM-1-positive cells. Cryo-sections of 7.5 days p.c. tissues were double-immunostained with anti-ChM-I antibody (green) and anti-PECAM-1 antibody (red), and counterstained with DAPI (panel D). All images are representative of at least three independent experiments. epc, ectoplacental cone; em, embryo; dec, decidua. Bars in panels A-C, $200 \mu \mathrm{m}$; Bar in panel D, $50 \mu \mathrm{m}$. the feto-maternal interface during implantation and decidualization. Invading trophoblasts express MMPs to facilitate matrix remodeling, and respond to a number of growth factors produced by the decidua. Concurrently, the maternal vasculature is also stimulated and directed to the implanted embryo by angiogenic factors produced in the decidua [13-15]. RT-PCR indicated that decidual cells expressed angiogenic growth factors such as VEGF-A, FGF-2 (fibroblast growth factor-2), and IGF-I (insulin-like growth factor-I), whilst EPCs were positive for their cognate receptors (Figure 4). Moreover, EPCs predominantly expressed MMP-9, a molecule believed to be crucial for tissue remodeling. In contrast, cultured decidual cells expressed all of TIMPs that were

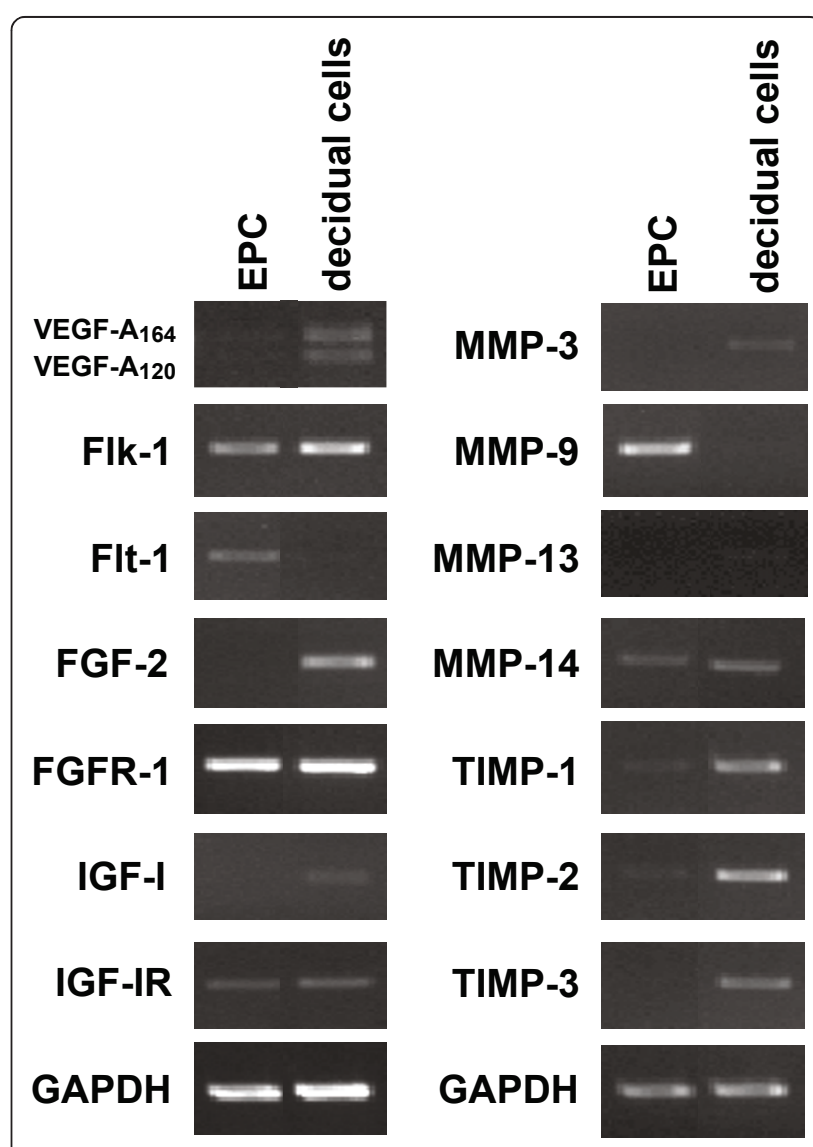

Figure 4 Expression profiles of angiogenesis- and matrix remodeling-related genes in cultured EPCs and decidual cells. EPCs and decidual cells were isolated from decidual capsules at 7.5 days p.c. Decidual cells $\left(5 \times 10^{5}\right.$ cells/well in 6 -multiwell plates) and EPCs (10 EPCs/well in 6-multiwell plates) were cultured in DMEM containing 10\% FBS for 2-5 days, respectively. Total RNA was isolated, reverse-transcribed, and the indicated sets of genes associated with angiogenesis (left panel) and tissue remodeling (right panel) were analyzed by RT-PCR (25 cycles for VEGF-A, Flk-1, Flt-1, MMP-3, MMP-9, MMP-14, TIMP-1, TIMP-2, TIMP-3; 30 cycles for FGF-2, FGFR-1, IGF-1, IGF-IR, MMP-1). GAPDH (25 cycles) was used as an internal control. The data are representative of three independent experiments. 
examined (Figure 4). These results are compatible with the notion that trophoblasts are capable of responding to angiogenic and anti-angiogenic signal cues produced by the decidua.

\section{Induction of ChM-I expression by the decidualization of endometrial stromal cells in vitro}

Decidualized endometrial stromal cells swell up their cell volume and produce basement membrane-like ECMs such as type IV collagen, laminin, and fibronectin instead of the interstitial matrices [16,17]. To investigate the expression of ChM-I in decidual cells, the cells were enzymatically isolated from the decidual capsules of mice at 7.5 days p.c., and cultured for seven days in vitro in the presence of $10 \%$ fetal bovine serum (FBS). As previously reported $[18,19]$, the isolated cells were predominantly large, flattened, polygonal, and some were multi-nucleated (Figure 5A, arrowheads). The expression of ChM-I transcripts was monitored along with the detection of decidual cell-differentiation marker genes by RT-PCR (Figure 5B). While abundant type I collagen transcripts were detected only in undifferentiated endometrial stromal cells, a high level of type IV collagen was maintained in the cultured cells [17]. (Figure 5B). In contrast, the expression levels of Prl8a2 markedly declined (Figure 5B) during one week of culture, although no morphological changes of cells were

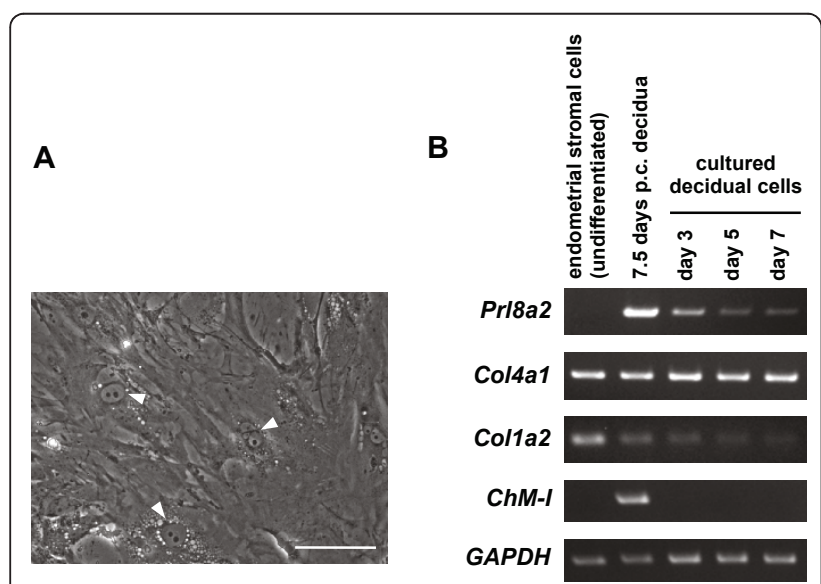

Figure $\mathbf{5}$ Loss of ChM-I expression in cultured decidual cells. (A) Decidual cells were enzymatically isolated from decidual capsules (7.5 days p.c.) and seeded at $5 \times 10^{5}$ cells/well in a 6-multiwell plate. The cells were then cultured for seven days in DMEM containing 10\% FBS. Arrowheads indicate cells that have multipleor enlarged nuclei, which are characteristic of the differentiated decidual cells. Bars, $100 \mu \mathrm{m}$. (B) Total RNA was isolated from decidual cell cultures at the indicated time points, endometrial stromal cells cultured for three days, and decidual tissue at 7.5 days p.c. One microgram of total RNA was reverse-transcribed, and the expression of ChM-I, Prl8a2, Col4a1, and Colla2 was analyzed by RTPCR (25 cycles for Prl8a2, Col4a1, Col1a2; 35 cycles for ChM-I). The data are representative of three independent experiments. apparent. Expression of ChM-I was readily detectable in the 7.5 days p.c. decidual capsules, but the capacity for $C h M-I$ expression was only barely maintained when decidual cells were transferred into culture.

Kimura and coworkers have demonstrated previously that mouse endometrial stromal cells undergo decidualization in vitro in the presence of $17 \beta$-estradiol (E2) and progesterone (P4) [20]. We isolated endometrial stromal cells from 4-week-old immature female mice using their protocol [20], and cultured the cells with or without E2 and P4. Without E2 $(0.1 \mathrm{nM})$ and P4 $(100 \mathrm{nM})$, endometrial stromal cells retained the spindle-shaped morphology of fibroblasts throughout the culture period. However, when cultured in the presence of E2 and P4, these cells adopted rounded morphologies with enlarged and/or multiple nuclei (Figure 6A, arrowheads), resembling the decidual cells in culture shown in Figure 5A. RT-PCR analysis of total RNA from cells indicated that there was no apparent expression of ChM-I when the cells were cultured without E2 and P4 (Figure 6B). In contrast, ChM-I and Prlsa2 transcripts were induced by the addition of E2 and P4 to these cultures, even though the expression level was relatively low compared with that of the decidua at 7.5 days p.c. (Figure 6B). In situ hybridization to the cultured cells revealed that no hybridization signals were present in spindle-shaped endometrial stromal cells cultured without E2 and P4, but that hypertrophic rounded cells with enlarged and/ or multiple nuclei formed in the presence of E2 and P4 exhibited positive signals for Prl8a2 mRNA as a result of decidualization (Figure 6C). Positive immunoreactivity to ChM-I protein was readily detected also in these decidualized hypertrophic cells (Figure 6D, arrowheads), but not without E2 and P4. These results indicate that ChM-I is induced in association with the decidualization of endometrial stromal cells.

\section{Effects of rhChM-I on the migration of Rcho-1 trophoblast cells}

Taking advantage of rat Rcho-1 trophoblast cells, which are capable of recapitulating trophoblast giant cell differentiation in vitro [21], we examined whether recombinant human ChM-I (rhChM-I) affects the chemotactic migration of trophoblasts. In the growth medium, Rcho-1 trophoblast cells retained an undifferentiated state with a low level of expression of genes such as Prl3d1, a marker for trophoblast differentiation, and $M M P-9$, a terminal differentiation associated marker (day 0, Figure 7A). When the cells reached confluence, the culture medium was replaced with differentiation medium containing horse serum. Expression of these marker genes evidently increased by day 7 (Figure 7A). No ChM-I transcripts were detected in cells cultured in either growth or differentiation medium (Figure 7A). 

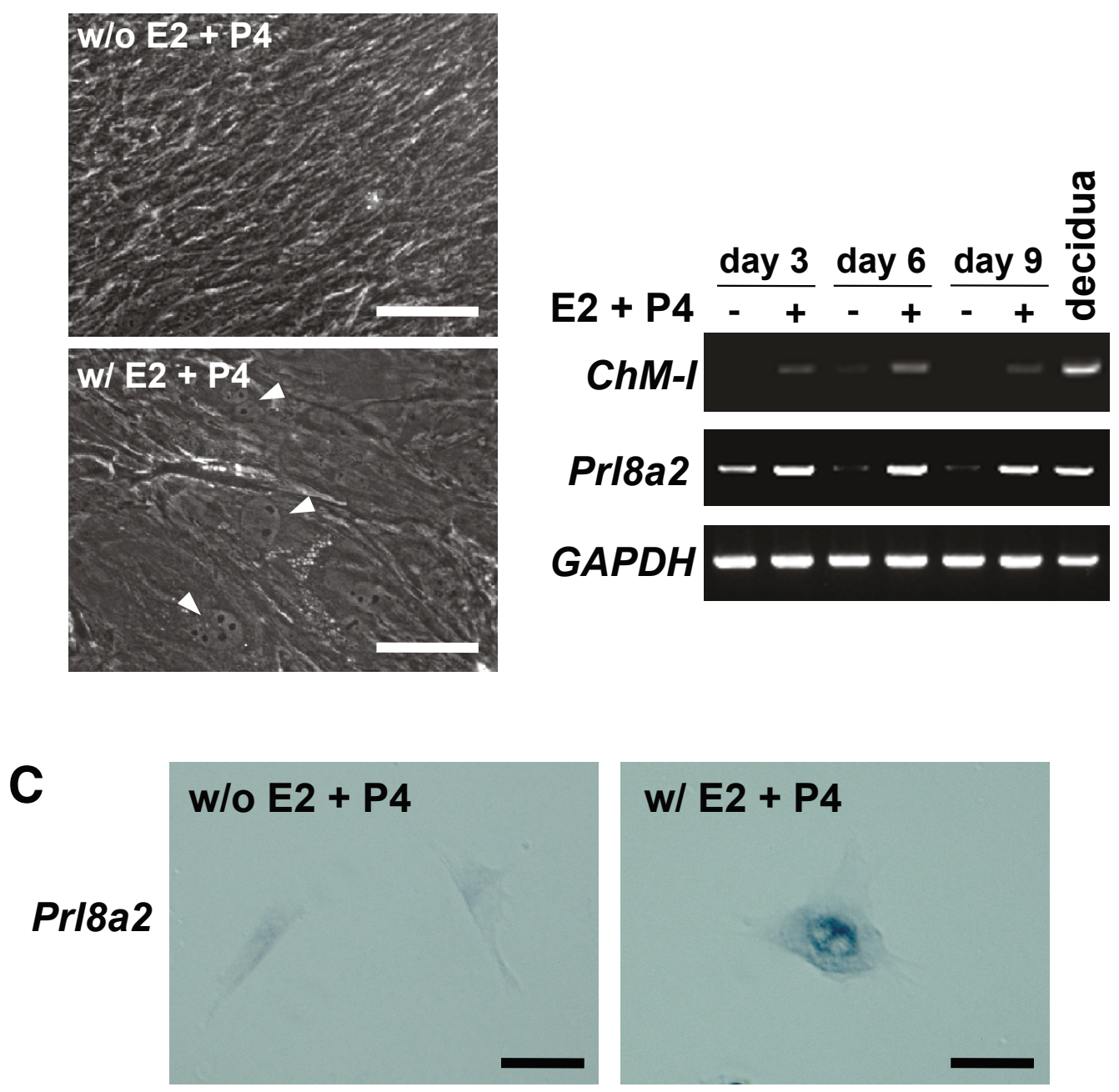

D
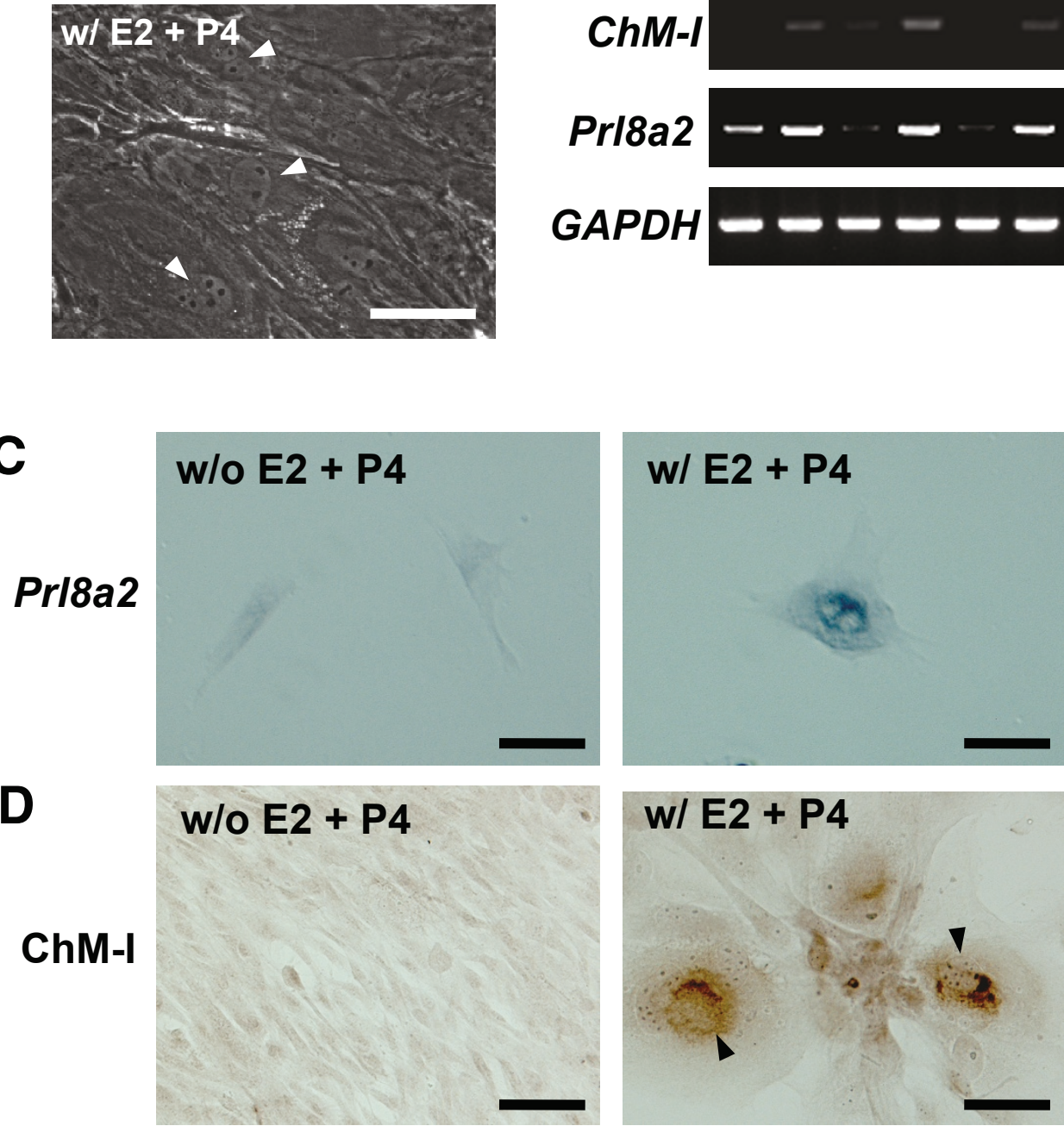

Figure 6 Induction of ChM-I expression during the decidualization of mouse endometrial stromal cells in vitro. Mouse endometrial stromal cells were enzymatically isolated from the uteri of 4 week-old non-pregnant mice and cultured in medium containing $10 \%$ charcoalstripped FBS. The in vitro decidualization of endometrial stromal cells was induced by the addition of E2 (0.1 nM) and P4 (100 nM) to the culture media. (A) Representative microphotographs of the endometrial stromal cells cultured for nine days in the presence (lower panel) or absence (upper panel) of E2 + P4. Arrowheads indicate enlarged or multi-nucleated cells that are characteristic of decidual cells. Bars, $50 \mu \mathrm{m}$. (B) Expression of ChM-I and Prlsa2 in decidualized cultures of endometrial stromal cells. Total RNA was extracted from the cells at the indicated time points and from mouse decidua (7.5 days p.c.). One microgram of each total RNA preparation was reverse-transcribed and analyzed by RT-PCR (35 cycles) for comparison. GAPDH was used as an internal control. (C, D) Expression of Prl8a2 gene in decidualized cells and immunostaining of ChM-I protein. The endometrial stromal cells were cultured for six days with or without E2 + P4, fixed, and subjected to in situ hybridization for Prl8a2 (C) and immunostaining with anti-ChM-I antibody (D). Note that intense signals for ChM-l protein (arrowheads) were observed in enlarged cells that also expressed Prl8a2. Bars, $30 \mu \mathrm{m}$. All images are representative of three independent experiments. 
A

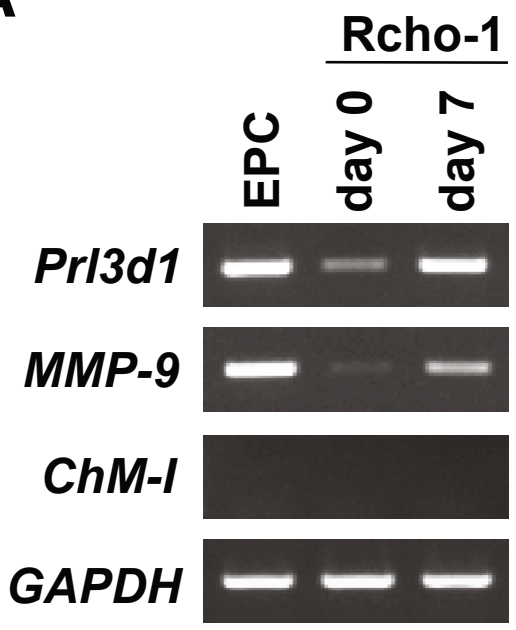

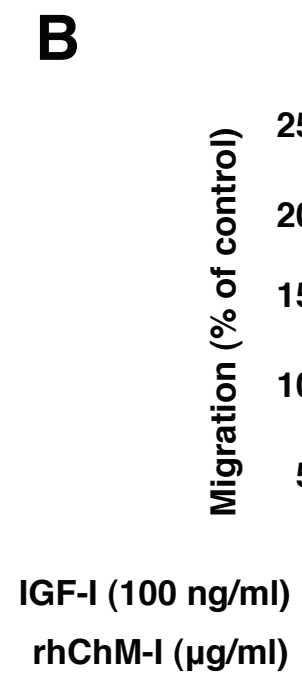

Figure 7 Effects of rhChM-I on the IGF-I-induced migration of Rcho-1 trophoblast cells. (A) Expression of Prl3d1, MMP-9, and ChM-I in Rcho-1 trophoblast cells. Rcho-1 trophoblast cells were seeded at $2 \times 10^{5}$ cells/well in 6-multiwell plates and cultured in growth medium (NCTC-135 medium containing 20\% FBS) until reaching confluence (day 0; undifferentiated). The culture medium was then replaced with differentiation medium (NCTC-135 medium containing 10\% horse serum), and the cells were cultured for seven days (day 7, differentiated) to promote their differentiation to trophoblast giant cells. EPCs were isolated at 7.5 days p.c. and cultured for two days in DMEM containing $10 \%$ FBS and 15 mM HEPES. Total RNA was then isolated and reverse-transcribed, and the expression of Prl3d1 (28 cycles), MMP-9 (28 cycles), and ChM-I (35 cycles) was analyzed by RT-PCR. GAPDH (28 cycles) was used as an internal control. The gel images are representative of three independent experiments. (B) Boyden chamber migration assay of Rcho- 1 trophoblast cells. Serum-starved Rcho- 1 trophoblast cells $\left(1 \times 10^{5}\right.$ cells/200 $\mu$ l) were preincubated with or without rhChM-I for 20 min, and then seeded onto fibronectin-coated cell culture inserts in NCTC-135 medium containing $0.5 \%$ FBS.

Chemotactic migration of Rcho-1 cells was induced by the addition of IGF-I (100 ng/ml) to the lower chamber. Cells were then allowed to migrate for $6 \mathrm{~h}$ in the presence of various concentrations of rhChM-I. Control cells were treated with $0.1 \%$ BSA/PBS and allowed to migrate in the absence of IGF-I. The number of cells that had invaded the undersurface of the insert was counted in five representative high power fields (under $\times 200$ magnification) per insert. The values shown are percentages of the number of migrated cells compared with the control cells ( $22 \pm 2.3$ cells/field) and are the means \pm SD of a triplicate assay. The data are representative of three independent experiments. The statistical significances were determined by the Student's t-tests as compared to IGF-I alone $\left({ }^{*} P<0.05\right.$, one-tailed).

The effects of rhChM-I were then tested using modified Boyden chambers. Subconfluent Rcho-1 trophoblast cells cultured in growth medium were serum-starved and seeded onto migration inserts that had been coated with fibronectin, one of the abundant matrix components in the decidua. Among the angiogenic growth factors expressed in the decidual cells (Figure 4), FGF-2 (data not shown) and IGF-I, but not VEGF-A, exhibited a pronounced stimulatory effect on the chemotactic migration of Rcho-1 trophoblast cells. IGF-I induced the migration of these cells by approximately two-fold over the non-stimulated basal levels (Figure 7B). In contrast, the addition of rhChM-I to the cultures clearly inhibited the IGF-I-induced migration of the cells in a dose-dependent manner. At a dose of $0.5 \mu \mathrm{g} / \mathrm{ml}$ or higher, IGF-I-induced migration was completely abolished (Figure 7B).

\section{Anti-invasive effects of rhChM-I upon Rcho- 1 trophoblast cells}

The invasive activity of Rcho-1 trophoblast cells was examined (Figure 8). Gelatin zymography revealed that
Rcho-1 trophoblast cells produced the active form of MMP-9 in association with their differentiation to trophoblast giant cells when the cells are cultured in differentiation medium containing 10\% horse serum (Figure 8A, upper panel). Activated MMP-9 was secreted as the predominant gelatinolytic activity, and MMP-2 and their zymogens were undetectable. GM6001 $(25 \mu \mathrm{M})$, an inhibitor of broad spectrum MMP, partially reduced the activation of pro-MMP-9, but the addition of rhChM-I in culture produced no apparent effect on the formation of activated MMP-9 (Figure 8A, lower panel). Despite this, rhChM-I clearly inhibited the invasion of differentiated Rcho-1 trophoblast cells into Matrigel in a dosedependent manner (Figure 8B). Rcho-1 trophoblast cells took on well-spread motile morphologies with active lamellipodia formation (Figure 8C, upper panel) and actively invaded a Matrigel layer in Boyden chamber (Figure $8 \mathrm{~B}$ ) under low serum conditions with $0.5 \%$ horse serum, which allow differentiation of the cells [21]. In the presence of rhChM-I, most cells took on quite distinctive static morphologies suggestive of their lower motility (Figure 8C, lower panel). 


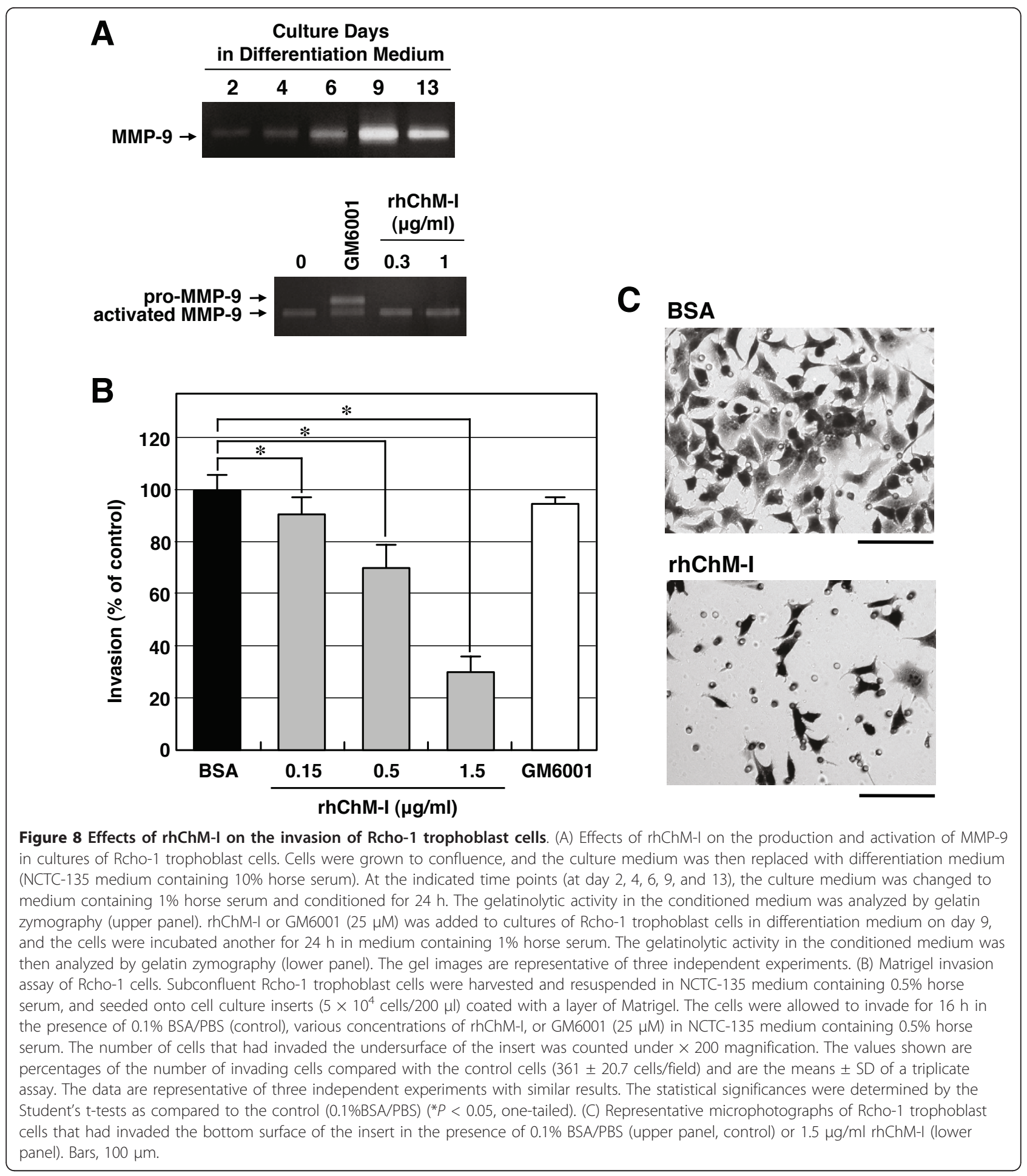

\section{Discussion}

Along with the invasion of trophoblasts into the maternal endometrium, sequential decidual reactions occur and lead to the formation of two distinct zones: the differentiated zone proximal to an implanting embryo termed the primary decidual zone, and the distal peripheral zone consisting of immature mitotic decidual cells, termed the secondary decidual zone [22,23]. In our present study, we have demonstrated that ChM-I is expressed in the primary decidual zone during early pregnancy in mice. In contrast to Prl8a2, which is broadly expressed in decidual tissue and strongly 
induced during decidualization [10], ChM-I transcripts were localized to well-differentiated decidual cells in the primary decidual zone and were not detectable in the secondary decidual zone. Consistent with this, ChM-I was induced in cultured endometrial stromal cells that were undergoing decidualization in the presence of estrogen and progesterone in vitro. Both ChM-I protein and Prl8a 2 mRNA were evident in the enlarged multinucleated well-differentiated cells in primary cultures of decidual cells [24].

The invasion of trophoblasts and maternal blood vessels are coordinately regulated in the primary decidual zone during early pregnancy. It has been known that the primary decidual zone remains to be vascularized prior to the invasion of trophoblasts [23]. Interestingly, ChM-I expression is predominantly detected at the mesometrial side of primary decidua facing the zone of vascularization, whereas the intense signals for TIMP-3 expression, another marker for well-differentiated decidual cells [25], were found at the antimesometrial side of primary decidua. When the trophoblasts were extensively detected along the margin of the implantation chamber at 7.5 days p.c., ChM-I was expressed at the entire zone of the primary decidua surrounding the invading trophoblasts, suggesting that ChM-I may participate in the invasion processes of trophoblasts.

The capacity for ECM degradation is one of the critical components required for the invasive behavior of cells $[26,27]$. Trophoblasts indeed express various kinds of proteinases, and proteinase inhibitors are localized in the decidua. For instance, it has been shown that TIMPs, cystatins, and plasminogen activator inhibitors are expressed in the distinct domains of the decidua $[25,28,29]$. In particular, MMP-9 and TIMP-3 are expressed at considerably high levels in the periphery of the implantation chamber and are thought to be pivotal regulators of ECM remodeling during the invasion of trophoblasts. However, trophoblast invasion proceeded relatively unhindered by the administration of a synthetic MMP inhibitor GM6001 into pregnant mice or the overexpression of TIMP-1 [14], while these treatments had led to a reduced size of the decidua and mesometrial displacement of an embryo. These observations are compatible with our present results showing that GM6001 had only a marginal inhibitory effect on the invasion of Rcho-1 trophoblast cells. TIMP-3 had also little impact on the Matrigel invasion of Rcho-1 trophoblast cells (data not shown). In contrast, ChM-I exhibited remarkable anti-invasive activity in the Matrigel invasion assay of Rcho-1 trophoblast cells, even though it did not interfere with the production and activation of gelatinases in the cells. The anti-invasive activity of rhChM-I was also evident in the Matrigel invasion of HUVECs [8], in which GM6001 was ineffective to block the invasion of cells (data not shown).

We have previously demonstrated that ChM-I inhibits the migration of vascular endothelial cells induced by angiogenic growth factors including VEGF-A, FGF2, and IGF-I [8]. As suggested by the present RT-PCR study, EPCs are also capable of responding to these growth factors. Indeed, it has been reported also that IGF-I is a potent stimulator of mouse EPC cells and human trophoblast migration [13,30,31]. Similarly, IGF-I and FGF-2, but not VEGF-A (data not shown), stimulated the migration of Rcho-1 trophoblast cells in culture. Using a modified Boyden chamber assay, we found that rhChM-I completely abolishes the IGF-Iinduced migration of Rcho-1 trophoblast cells. Morphologies of ChM-I-treated Rcho-1 trophoblast cells are also indicative of a critical reduction in cellular motility. This mode of ChM-I action is analogous to that on HUVECs [8]. Thus, ChM-I is likely to inhibit the invasion of Rcho-1 trophoblast cells and vascular endothelial cells by suppressing their cellular motility stimulated by IGF-I.

\section{Conclusions}

The present study demonstrates that ChM-I is expressed in the primary decidual zone during decidualization at feto-maternal interface. Recombinant ChM-I inhibited the migration and invasion of Rcho-1 trophoblast cells in a manner independent of MMP activation in vitro.

\section{Methods \\ Antibodies and reagents}

A purified rat anti-mouse CD31 (PECAM-1) monoclonal antibody was purchased from BD Pharmingen (San Diego, CA). A rabbit anti-ChM-I polyclonal antibody was raised against recombinant human ChM-I expressed in $\mathrm{CHO}$ cells [32]. Alexa Fluor 594-conjugated goat anti-rat IgG and Alexa Fluor 488-conjugated goat antirabbit IgG antibodies were obtained from Molecular Probes (Eugene, OR). E2 and P4 were purchased from Sigma (St. Louis, MO). GM6001 (a broad-spectrum MMP inhibitor) was obtained from Merck KGaA (Darmstadt, Germany). Growth factor reduced BD Matrigel Matrix and mouse recombinant IGF-I was purchased from BD Biosciences (Bedford, MA) and R\&D Systems (Minneapolis, MN), respectively.

\section{Expression and purification of recombinant human ChM-I}

Recombinant human ChM-I (rhChM-I; corresponding to the region $\mathrm{Glu}^{215}-\mathrm{Val}^{334}$ of the human ChM-I precursor) was expressed in a secreted form of an N-terminally FLAG-tagged fusion protein using the pCAGGS expression vector (generously donated by Dr. J. Miyazaki, Osaka University Graduate School of Medicine, Japan) 
[33]. The expression of rhChM-I under serum-free conditions and its purification from the culture supernatant were performed using the FreeStyle 293 Expression system (Invitrogen, Carlsbad, CA) and anti-FLAG M2 affinity gel (Sigma) according to the manufacturer's instructions [8].

\section{Tissue dissections}

Pregnant and non-pregnant C57 BL/6 female mice were purchased from SHIMIZU Laboratory Supplies (Kyoto, Japan). All experimental procedures involving the use of animals for experimental purposes were approved by the Animal Care Committee of the Institute for Frontier Medical Sciences (Kyoto University) in accordance with institutional guidelines under the protocol number E24-3. Mice were housed in a temperature and humidity controlled facility in Laboratory of Animal Experiments for Regeneration (Institute for Frontier Medical Sciences, Kyoto University) with a $12 \mathrm{~h}$ light/dark cycle and allowed access to food and water ad libitum. Female mice were checked for pregnancy by the presence of vaginal plugs in the morning (midnight $=0$ day p.c.) and sacrificed by cervical dislocation. Uteri were removed from pregnant mice, cut open, and decidual capsules were then teased out. Using thin-needled forceps, embryos were removed from the decidua, and EPCs (ectoplacental cones; detectable as a cone-shaped vascularized region) were carefully separated from the distal endoderm at 7.5 days p.c. The placenta was separated from the $\mathrm{C} 57 \mathrm{BL} / 6$ pregnant mice (13.5 days p.c.). Some decidual samples or EPCs were prepared from the EGFP-transgenic female mice [34] (kindly provided by Dr. Masaru Okabe, Research Institute for Microbial Diseases, Osaka University, Japan) mated with wild-type C57 BL/6 male mice to track invading trophoblast cells as reported by Rosario et al [35].

\section{Cell culture}

Isolation of decidual cells was carried out as described previously [36] with minor modifications. Briefly, decidual capsules were removed from ICR pregnant mice at 7.5 days p.c. and minced into small pieces in Hank's balanced salt solution-calcium/magnesium free. The minced tissues were then incubated at $37^{\circ} \mathrm{C}$ for 5 min in $0.05 \%$ type IV collagenase (Sigma) containing $0.02 \%$ deoxyribonuclease I (DNase I, Sigma), followed by incubation in $0.007 \%$ collagenase with $0.02 \%$ DNase I and $0.008 \%$ type XIV proteinase (Sigma) at $37^{\circ} \mathrm{C}$ for $5 \mathrm{~min}$. The tissues were then triturated, and the supernatant was centrifuged at $1000 \mathrm{rpm}$ for $5 \mathrm{~min}$. Cell pellets were suspended in Dulbecco's modified Eagle medium (DMEM; Sigma) containing 10\% FBS, and the cells were seeded at $5 \times 10^{5}$ cells/well in 6 -multiwell plates.
Mouse endometrial stromal cells were isolated and cultured as previously described with minor modifications [20]. Briefly, uteri were removed from immature 4week-old ICR mice, slit longitudinally to expose the endometrial surface, and minced into small pieces in PBS. The minced tissues were then incubated in $0.25 \%$ type IV collagenase (Sigma) and $0.3 \%$ bovine serum albumin (BSA; Sigma) in PBS for $1 \mathrm{~h}$ at $37^{\circ} \mathrm{C}$. After enzymatic digestion, the supernatant was passed through a $40-\mu \mathrm{m}$ cell strainer (BD Biosciences), centrifuged at $1000 \mathrm{rpm}$ for $5 \mathrm{~min}$, and the pelleted cells were rinsed with phenol red-free DMEM. The cells were then resuspended in DMEM supplemented with 10\% charcoalstripped FBS, $100 \mathrm{U} / \mathrm{ml}$ penicillin and $100 \mu \mathrm{g} / \mathrm{ml}$ streptomycin, seeded at $7.5 \times 10^{5}$ cells/well in 6 -multiwell plates, and incubated in a humidified atmosphere of $5 \%$ $\mathrm{CO}_{2}$ in air for $1 \mathrm{~h}$. After the $1 \mathrm{~h}$ incubation, unattached cells were gently removed with medium. For the in vitro decidualization, endometrial stromal cells were cultured with or without E2 and P4 at a concentration of $0.1 \mathrm{nM}$ and $100 \mathrm{nM}$, respectively. The culture medium was changed every other day.

Rcho-1 trophoblast cells were obtained from Dr. M. J. Soares (University of Kansas Medical Center, Kansas City, USA) [21,37]. The cells were maintained in NCTC-135 medium (Sigma) supplemented with $10 \mathrm{mM}$ HEPES, $50 \mu \mathrm{M} \beta$-mercaptoethanol (Sigma), $1 \mathrm{mM}$ sodium pyruvate (Sigma), $50 \mu \mathrm{g} / \mathrm{ml}$ kanamycin sulfate (Sigma), and 20\% FBS (growth medium). For the induction of differentiation, Rcho- 1 cells in confluent culture were maintained in NCTC-135 medium containing 10\% horse serum (GIBCO; differentiation medium). The culture medium was changed every other day. EPCs dissected from decidua at 7.5 days p.c. were cultured in DMEM supplemented with $10 \% \mathrm{FBS}$ and $15 \mathrm{mM}$ HEPES at $37^{\circ} \mathrm{C}$ under $5 \% \mathrm{CO}_{2}$ in air.

\section{RNA preparation and RT-PCR}

Total RNA extracts were prepared from tissues and cells using the single step method of Chomczynski and Sacchi [38]. First strand cDNA was synthesized from $1 \mu \mathrm{g}$ of total RNA using SuperScript II RNase H-reverse transcriptase (Gibco BRL, Grand Island, NY). The amplification of glyceraldehyde-3-phosphate-dehydrogenase (GAPDH) gene was utilized as an internal control. The primers used for RT-PCR are listed in Table 1.

\section{cDNA fragments for hybridization}

A 739 bp fragment of mouse ChM-I (GenBank accession no. NM_010701) cDNA was amplified from cDNAs prepared from differentiated ATDC5 cells by RT-PCR and subcloned into pCRII TOPO TA cloning vector (Invitrogen). A 515 bp fragment of the mouse TIMP-3 (tissue inhibitor of metalloproteinase-3; GenBank 
Table 1 Primers for RT-PCR analysis

\begin{tabular}{|c|c|c|c|c|}
\hline Genbank acc no. & Gene & 5'-Forward primer-3' & 5'-Reverse primer-3' & Size (bp) \\
\hline NM_010701 & ChM-I & CATCGGGGCCTTCTACTTCT & CTGCGTCGTCCTGAACATTGGG & 584 \\
\hline NM_010088 & Prl8a2 & TGAATGTCAAACAGGAGAGAA & CAATCTTGCCCAGTTATGCGG & 628 \\
\hline NM_008864 & Prl3d1 & GCTTCCATCCATACTCCAG & TCGTTCTGAAAGACAACTCG & 419 \\
\hline NM_009309 & Brachyury & CTGCAGTCCCATGATAACTGGTCTAGC & CCAGGATTTCAAAGTCACATATATGTTGTAG & 717 \\
\hline NM_009931 & Col4a1 & TGTCCAAGGCAACGAGCGTG & TGTTCTTCTCATGCACACTTGG & 583 \\
\hline NM_007742 & Col1a2 & GAACGGTCCACGATTGCATG & GGCATGTTGCTAGGCACGAAG & 401 \\
\hline NM_001025250 & VEGF-A & CAGAGAGCAACATCACCATGC & TCCTCGAAGGATCTCCTCTTCC & 313,445 \\
\hline NM_010612 & Flk-1 & CACAGACACCACCGTGTACTCC & CTCCAAGGTAGACAGACTCGGC & 516 \\
\hline NM_010228 & Flt-1 & TATGGTCTGTGTGCTTAGGTCG & ACAGGACCATCTATGGTCTTCC & 476 \\
\hline NM_008006 & FGF-2 & AGCGGCATCACCTCGCTTCC & TGGAAGCAGTATGGCCTTCTGTCC & 433 \\
\hline NM_010206 & FGFR-1 & AGAGACCAGCTGTGATGA & GGCCACTTTGGTCACACG & 461 \\
\hline NM_010512 & IGF-I & GGACCAGAGACCCTTTGCGGGG & GGCTGCTTITGTAGGCTTCAGTGG & 210 \\
\hline NM_010513 & IGF-IR & ATGCTGTTTGAACTGCAGCGCATGTGCTGG & CCGCTCGAGCTTGCGGCCCCCGTTCAT & 354 \\
\hline NM_010809 & MMP-3 & GAAATGCAGAAGTTCCTCGG & GAGTTCCATAGAGGGACTGA & 878 \\
\hline NM_013599 & MMP-9 & TGTCATCCAGTTTGGTGTCG & TAGGGCAGAAGCCATACAGT & 433 \\
\hline NM_008607 & MMP-13 & TGAAGAGACTGAGCGCTGCG & ATTCTTCCATGTGGTTCCAGCC & 461 \\
\hline NM_008608 & MMP-14 & ATCATTGAGGTGGATGAGGAGG & CAGCCAACCAGGTACACTTGG & 614 \\
\hline NM_001044384 & TIMP-1 & AGTAAGGCCTGTAGCTGTGCC & ACGAGGACCTGATCCGTCC & 467 \\
\hline NM_011594 & TIMP-2 & AGCAGTGAGCGAGAAGGAGG & TCACTTCTCTCGATGCAGGC & 450 \\
\hline NM_011595 & TIMP-3 & GCTACTGCAGCTGGTACCG & TTGGACTTCTGCCAACTTCC & 518 \\
\hline NM008084 & GAPDH & ACCACAGTCCATGCCATCAC & TCCACCACCCTGTTGCTGTA & 452 \\
\hline
\end{tabular}

accession no. NM_011595) cDNA and a 433 bp fragment of mouse MMP-9 (matrix metalloproteinase-9; GenBank accession no. NM_013599) were amplified from Mouse 17-day Embryo Marathon-Ready cDNA (Clontech, Palo Alto, CA). Both of the amplified cDNA fragments were then subcloned into the PCRII TOPO vector. Similarly, a 628 bp cDNA fragment of mouse Prl8a2 (prolactin family 8 , superfamily a, member 2 , also known as decidual/trophoblast prolactin-related protein; Gene accession number: NM_010088) was amplified using cDNA from 7.5 days p.c. decidua, and subcloned. A 551 bp cDNA fragment of mouse Prl3d1 (prolactin family 3, superfamily d, member 1 , also known as placental lactogen-I; Gene accession number: NM_008864) was also amplified using cDNAs prepared from 7.5 days p.c. EPCs, and subcloned. The partial 624 bp cDNA fragment of mouse VEGF-A 164 (Gene accession number: NM_001025250) was amplified from Mouse 11-day Embryo Marathon-Ready cDNA by RT-PCR and subcloned into pBluescriptII SK (+) at the NotI site. The primers used are listed in Table 2.

\section{Northern blot analysis}

Total RNA $(15 \mu \mathrm{g})$ was denatured with $6.5 \%$ formaldehyde, resolved on a $1 \%$ formaldehyde-agarose gel, transferred onto a nytran membrane (Schleicher \& Schuell, Dassel, Germany), and cross-linked by UV irradiation. The cDNA fragments for hybridization probes were labeled with $\left[\alpha-{ }^{32} \mathrm{P}\right]$ dCTP (Amersham Biosciences, Piscataway, NJ) by the random-primer method using a BcaBEST labeling kit (Takara, Shiga, Japan). Hybridization was carried out as described previously [39].

\section{In situ hybridization}

Tissues samples were fixed with $4 \%$ paraformaldehyde (PFA)/PBS for $16 \mathrm{~h}$ at $4^{\circ} \mathrm{C}$, embedded in paraffin, and cut at a thickness of $6 \mu \mathrm{m}$. The sections were dewaxed, rehydrated, treated with $10 \mu \mathrm{g} / \mathrm{ml}$ Proteinase K (Invitrogen) for $10-30 \mathrm{~min}$ at $25^{\circ} \mathrm{C}$. For the cultured endometrial stromal cells, the cells were briefly fixed with $4 \%$ PFA/PBS at room temperature. Antisense and sense riboprobes for each gene were prepared with appropriate cDNA fragments, and labeled using a digoxygenin (DIG) RNA labeling kit (Roche, Mannheim, Germany). Hybridization was carried out at $50^{\circ} \mathrm{C}$ for $16 \mathrm{~h}$ in hybridization buffer containing $600 \mathrm{mM} \mathrm{NaCl}, 10 \%$ dextran sulfate, $1 \times$ Denhardt's solution, $50 \%$ deionized formamide, $200 \mathrm{mg} / \mathrm{ml}$ tRNA, $10 \mathrm{mM}$ Tris- $\mathrm{HCl}$ (pH7.5), and $1 \mathrm{mM}$ EDTA. Sections were then rinsed under high stringency. Hybridization signals were detected immunohistochemically using an alkaline-phosphate-conjugated antibody, according to the manufacturer's instructions (Roche Diagnostics). 
Table 2 Primers for cDNA fragment cloning

\begin{tabular}{|c|c|c|c|c|}
\hline Genbank acc no. & Gene & 5'-Forward primer-3' & $5^{\prime}$-Reverse primer- $3^{\prime}$ & $\begin{array}{l}\text { Size } \\
\text { (bp) }\end{array}$ \\
\hline NM_010701 & ChM-I & GGGTCAATGGAAATAGATGCT & ACACCATGCCCAGGATGCGG & 739 \\
\hline NM_011595 & TIMP-3 & GCTACTGCAGCTGGTACCG & TTGGACTTCTGCCAACTTCC & 515 \\
\hline NM_013599 & MMP-9 & GATGCTATTGCTGAGATCCAGG & GGAAGATGTCGTGTGAGTTCC & 433 \\
\hline NM_008864 & Prl3d1 & GACCTGTATACTCGTITGGC & TCGTTCTGAAAGACAACTCG & 551 \\
\hline NM_010088 & Prl8a2 & TGAATGTCAAACAGGAGAGAA & CAATCTTGCCCAGTTATGCGG & 628 \\
\hline NM_001025250 & VEGF-A & ${ }^{*}$ GAAACCATGAACTTTCTGCTCTC & *GGTGAGAGGTCTGGTTCCCG & 624 \\
\hline
\end{tabular}

* The following sequence was added at the $5^{\prime}$-end of the primer. Added sequence: ATAAGAATGCGGCCGC

\section{Immunohistochemistry}

Tissue samples were passed through a series of sucrose/ PBS solutions $(12 \%, 15 \%$, and $18 \%)$, frozen in O.C.T. compound (Sakura Finetek \& Tissue-Tek, Tokyo, Japan), and cryo-sectioned at a thickness of $8 \mu \mathrm{m}$. The frozen sections were then fixed with 4\% PFA/PBS for 10 min at room temperature, rinsed with TBST (Tris-buffered saline containing $1 \%$ Tween 20), and incubated at $4{ }^{\circ} \mathrm{C}$ overnight with primary antibody. For immunofluorescent staining, the sections were incubated with Alexa Fluor 488-conjugated goat anti-mouse IgG secondary antibody (1:300 dilution) or Alexa Fluor 594-conjugated goat anti-rat IgG secondary antibody (1:300 dilution), and $1 \mu \mathrm{g} / \mathrm{ml}$ of 4', 6-diamidino-2-phenylindole (DAPI, Sigma) in $2 \%$ skim milk/PBS. The slides were then washed with TBST and observed under a fluorescent microscope.

\section{Matrigel invasion assay}

Both the upper and under surfaces of cell culture inserts ( $8 \mu \mathrm{m}$-sized pore filter; BD Biosciences) were coated with fibronectin ( $5 \mu \mathrm{g} / \mathrm{ml}$; BD Biosciences) for 4 $\mathrm{h}$ at room temperature. An amount of $100 \mu \mathrm{l}$ of 0.5 $\mathrm{mg} / \mathrm{ml}$ growth factor-reduced Matrigel (BD Biosciences) in PBS was then added to the upper compartment of the insert, followed by an incubation for $6 \mathrm{~h}$ at room temperature to solidify the gel. When grown to subconfluence, Rcho-1 trophoblast cells were harvested with trypsin/EDTA, and re-suspended in NCTC-135 medium containing $0.5 \%$ horse serum at $2.5 \times 10^{5}$ cells $/ \mathrm{ml}$. The cells $\left(5 \times 10^{4}\right.$ cells $\left./ 200 \mu \mathrm{l}\right)$ were seeded onto the Matrigel-coated cell culture insert and incubated at $37^{\circ} \mathrm{C}$ in $5 \% \mathrm{CO}_{2}$ for $16-18 \mathrm{~h}$. The test reagent (rhChM-I or GM6001) was added to both the upper $(200 \mu \mathrm{l})$ and lower chamber $(600 \mu \mathrm{l})$. After incubation for $16 \mathrm{~h}$, the cells were fixed for 15 min with $0.25 \%$ glutaraldehyde, and stained with Giemsa staining solution. Non-invading cells remaining on the upper surface of the insert were wiped off, and the number of cells that had invaded the undersurface of the insert was counted for five representative high power fields (under $\times 200$ magnification) per insert.

\section{Cell migration assay}

The migration of Rcho- 1 trophoblast cells was evaluated using a modified Boyden chamber assay. The upper and under surfaces of the cell culture inserts $(5 \mu \mathrm{m}$-sized pore filter, BD Biosciences) were coated with fibronectin $(5 \mu \mathrm{g} / \mathrm{ml})$ at $4^{\circ} \mathrm{C}$ overnight. Subconfluent Rcho- 1 trophoblast cells were harvested and resuspended in NCTC-135 medium containing $0.5 \%$ FBS $\left(1 \times 10^{5}\right.$ cells/ $200 \mu \mathrm{l})$. The cells were then preincubated with or without rhChM-I for $20 \mathrm{~min}$ and seeded onto the upper surface of the inserts. Chemotactic migration of the cells was induced by the addition of IGF-I $(100 \mathrm{ng} / \mathrm{ml})$ in the lower chamber $(600 \mu \mathrm{l})$. The cells were then allowed to migrate for $6 \mathrm{~h}$ at $37^{\circ} \mathrm{C}$ in the presence or absence of rhChM-I. The number of cells that had migrated to the undersurface of the insert was counted in five representative fields at a higher magnification ( $\times 200$ magnification) per insert.

\section{Gelatin zymography}

Gelatinolytic activity in the conditioned medium of Rcho-1 trophoblast cell cultures was assessed by gelatin zymography. Rcho- 1 trophoblast cells were seeded at 2 $\times 10^{5}$ cells/well in 6-multiwell plates and grown to confluence in growth medium. The culture medium was then replaced with differentiation medium and the cells were maintained for a further 13 days. The cells were then conditioned at the indicated time points for $24 \mathrm{~h}$ in NCTC-135 medium containing 1\% horse serum with or without test reagent. The conditioned media were centrifuged, and the supernatants were mixed with the same volume of $\times 2$ non-reducing SDS sample buffer [125 mM Tris- $\mathrm{HCl}$ (pH6.8), 20\% glycerol, and 4\% SDS]. The samples were next separated on a 7.5\% SDS-polyacrylamide gel containing $2 \mathrm{mg} / \mathrm{ml}$ gelatin (Sigma). After electrophoresis, the gel was rinsed twice in $2.5 \%$ Triton $\mathrm{X}-100$ to remove the SDS, then incubated in $50 \mathrm{mM}$ Tris- $\mathrm{HCl}$ (pH8.0) buffer containing $5 \mathrm{mM} \mathrm{CaCl}_{2}$ to allow gelatinolysis for 16-20 h. Gels were stained with Coomassie Brilliant Blue R-250. The clearing of background gelatin by proteinases revealed gelatinolysis as clear bands. 


\section{Acknowledgements}

We thank Dr. M. J. Soares (University of Kansas Medical Center) and Dr. M. Okabe (Osaka University, Research Institute for Microbial Diseases) for providing Rcho-1 trophoblast cells and EGFP transgenic mice, respectively. This work was supported by the Grants-in-aid from the Ministry of Education, Culture, Sports, Science, and Technology of Japan (Y.H.)

\section{Author details}

${ }^{1}$ Department of Cellular Differentiation, Institute for Frontier Medical Sciences, Kyoto University, Kyoto 606-8507, Japan. ${ }^{2}$ Research and Development Division, Science and Technology Research Center Inc., Mitsubishi Chemical Group, Kanagawa 227-8502, Japan. ${ }^{3}$ Advanced Medical Research Laboratory, Research Division, Mitsubishi Tanabe Pharma Corporation, Kanagawa 227-0033, Japan.

\section{Authors' contributions}

SM participated in the design of the study, performed the main experimental work, analyzed the data, and drafted the manuscript. CS conceived the study, participated in its design coordination and carried out northern blot analysis. KM and JK carried out the cell invasion assay and analyzed the data. YH coordinated the study and wrote the manuscript. All authors read and approved the final manuscript.

Received: 18 May 2011 Accepted: 18 August 2011

Published: 18 August 2011

\section{References}

1. Funaki H, Sawaguchi S, Yaoeda K, Koyama Y, Yaoita E, Funaki S, Shirakashi M, Oshima Y, Shukunami C, Hiraki Y, et al: Expression and localization of angiogenic inhibitory factor, chondromodulin-l, in adult rat eye. Invest Ophthalmol Vis Sci 2001, 42(6):1193-1200.

2. Yoshioka M, Yuasa S, Matsumura K, Kimura K, Shiomi T, Kimura N, Shukunami C, Okada Y, Mukai M, Shin H, et al: Chondromodulin-I maintains cardiac valvular function by preventing angiogenesis. Nat Med 2006, 12(10):1151-1159.

3. Shukunami C, Takimoto A, Miura S, Nishizaki Y, Hiraki Y: Chondromodulin-I and tenomodulin are differentially expressed in the avascular mesenchyme during mouse and chick development. Cell Tissue Res 2008, 332(1):111-122.

4. Hiraki Y, Inoue H, lyama K, Kamizono A, Ochiai M, Shukunami C, lijima S, Suzuki F, Kondo J: Identification of chondromodulin I as a novel endothelial cell growth inhibitor. Purification and its localization in the avascular zone of epiphyseal cartilage. J Biol Chem 1997, 272(51):32419-32426.

5. Hiraki Y, Kono T, Sato M, Shukunami C, Kondo J: Inhibition of DNA synthesis and tube morphogenesis of cultured vascular endothelial cells by chondromodulin-I. FEBS Lett 1997, 415(3):321-324.

6. Hayami T, Shukunami C, Mitsui K, Endo N, Tokunaga K, Kondo J, Takahashi HE, Hiraki Y: Specific loss of chondromodulin-I gene expression in chondrosarcoma and the suppression of tumor angiogenesis and growth by its recombinant protein in vivo. FEBS Lett 1999, 458(3):436-440.

7. Oshima Y, Sato K, Tashiro F, Miyazaki J, Nishida K, Hiraki Y, Tano Y, Shukunami C: Anti-angiogenic action of the C-terminal domain of tenomodulin that shares homology with chondromodulin-I. J Cell SCi 2004, 117(Pt 13):2731-2744.

8. Miura S, Mitsui K, Heishi T, Shukunami C, Sekiguchi K, Kondo J, Sato Y, Hiraki Y: Impairment of VEGF-A-stimulated lamellipodial extensions and motility of vascular endothelial cells by chondromodulin-I, a cartilagederived angiogenesis inhibitor. Exp Cell Res 2010, 316(5):775-788.

9. Shukunami C, lyama K, Inoue H, Hiraki Y: Spatiotemporal pattern of the mouse chondromodulin-I gene expression and its regulatory role in vascular invasion into cartilage during endochondral bone formation. Int J Dev Biol 1999, 43(1):39-49.

10. Orwig KE, Ishimura R, Muller H, Liu B, Soares MJ: Identification and characterization of a mouse homolog for decidual/trophoblast prolactinrelated protein. Endocrinology 1997, 138(12):5511-5517.

11. Wilkinson DG, Bhatt S, Herrmann BG: Expression pattern of the mouse $T$ gene and its role in mesoderm formation. Nature 1990, 343(6259):657-659.

12. Hu D, Cross JC: Development and function of trophoblast giant cells in the rodent placenta. Int J Dev Biol 2010, 54(2-3):341-354.
13. Kanai-Azuma M, Kanai Y, Kurohmaru M, Sakai S, Hayashi Y: Insulin-like growth factor (IGF)-I stimulates proliferation and migration of mouse ectoplacental cone cells, while IGF-II transforms them into trophoblastic giant cells in vitro. Biol Reprod 1993, 48(2):252-261.

14. Salamonsen LA: Role of proteases in implantation. Rev Reprod 1999, 4(1):11-22.

15. Dey SK, Lim H, Das SK, Reese J, Paria BC, Daikoku T, Wang H: Molecular cues to implantation. Endocr Rev 2004, 25(3):341-373.

16. Rinkenberger $\mathrm{JL}$, Cross JC, Werb Z: Molecular genetics of implantation in the mouse. Dev Genet 1997, 21(1):6-20,

17. Wewer UM, Damjanov A, Weiss J, Liotta LA, Damjanov I: Mouse endometrial stromal cells produce basement-membrane components. Differentiation 1986, 32(1):49-58.

18. Babiarz BS, Romagnano LC, Kurilla GM: Interaction of mouse ectoplacental cone trophoblast and uterine decidua in vitro. Vitro Cell Dev Biol 1992, 28A(7-8):500-508.

19. Babiarz B, Romagnano L, Afonso S, Kurila G: Localization and expression of fibronectin during mouse decidualization in vitro: mechanisms of cell: matrix interactions. Dev Dyn 1996, 206(3):330-342.

20. Kimura F, Takakura K, Takebayashi K, Ishikawa H, Kasahara K, Goto S, Noda Y: Messenger ribonucleic acid for the mouse decidual prolactin is present and induced during in vitro decidualization of endometrial stromal cells. Gynecol Endocrinol 2001, 15(6):426-432.

21. Peters TJ, Albieri A, Bevilacqua E, Chapman BM, Crane LH, Hamlin GP, Seiki M, Soares MJ: Differentiation-dependent expression of gelatinase B/ matrix metalloproteinase-9 in trophoblast cells. Cell Tissue Res 1999, 295(2):287-296.

22. Schlafke S, Enders AC: Cellular basis of interaction between trophoblast and uterus at implantation. Biol Reprod 1975, 12(1):41-65.

23. Tung HN, Parr MB, Parr EL: The permeability of the primary decidual zone in the rat uterus: an ultrastructural tracer and freeze-fracture study. Biol Reprod 1986, 35(4):1045-1058.

24. Stewart I, Mukhtar DD: The morphology of cultured cells from the mouse endometrium and decidua. J Anat 1988, 156:197-206.

25. Alexander CM, Hansell EJ, Behrendtsen O, Flannery ML, Kishnani NS, Hawkes SP, Werb Z: Expression and function of matrix metalloproteinases and their inhibitors at the maternal-embryonic boundary during mouse embryo implantation. Development 1996, 122(6):1723-1736.

26. Westermarck J, Kahari VM: Regulation of matrix metalloproteinase expression in tumor invasion. Faseb J 1999, 13(8):781-792.

27. Egeblad M, Werb Z: New functions for the matrix metalloproteinases in cancer progression. Nat Rev Cancer 2002, 2(3):161-174.

28. Wang $S$, Kennedy TG, Zhang X: Presence of urokinase plasminogen activator and plasminogen activator inhibitor-1 messenger ribonucleic acids in rat endometrium during decidualization in vivo. Biol Reprod 1996, 55(3):493-497.

29. Afonso $S$, Romagnano L, Babiarz B: The expression and function of cystatin $C$ and cathepsin B and cathepsin L during mouse embryo implantation and placentation. Development 1997, 124(17):3415-3425.

30. Kabir-Salmani M, Shiokawa S, Akimoto Y, Hasan-Nejad H, Sakai K, Nagamatsu S, Nakamura Y, Hosseini A, Iwashita M: Characterization of morphological and cytoskeletal changes in trophoblast cells induced by insulin-like growth factor-I. J Clin Endocrinol Metab 2002, 87(12):5751-5759.

31. Lacey H, Haigh T, Westwood M, Aplin JD: Mesenchymally-derived insulinlike growth factor 1 provides a paracrine stimulus for trophoblast migration. BMC Dev Biol 2002, 2:5.

32. Hiraki Y, Mitsui K, Endo N, Takahashi K, Hayami T, Inoue H, Shukunami C, Tokunaga K, Kono T, Yamada M, et al: Molecular cloning of human chondromodulin-l, a cartilage-derived growth modulating factor, and its expression in Chinese hamster ovary cells. Eur J Biochem 1999, 260(3):869-878.

33. Niwa $\mathrm{H}$, Yamamura K, Miyazaki J: Efficient selection for high-expression transfectants with a novel eukaryotic vector. Gene 1991, 108(2):193-199.

34. Okabe M, Ikawa M, Kominami K, Nakanishi T, Nishimune Y: 'Green mice' as a source of ubiquitous green cells. FEBS Lett 1997, 407(3):313-319.

35. Rosario GX, Konno T, Soares MJ: Maternal hypoxia activates endovascular trophoblast cell invasion. Dev Biol 2008, 314(2):362-375.

36. Afonso S, Tovar C, Romagnano L, Babiarz B: Control and expression of cystatin C by mouse decidual cultures. Mol Reprod Dev 2002, 61(2):155-163. 
37. Faria TN, Soares MJ: Trophoblast cell differentiation: establishment, characterization, and modulation of a rat trophoblast cell line expressing members of the placental prolactin family. Endocrinology 1991, 129(6):2895-2906.

38. Chomczynski P, Sacchi N: Single-step method of RNA isolation by acid guanidinium thiocyanate-phenol-chloroform extraction. Anal Biochem 1987, 162(1):156-159

39. Shukunami $C$, Hiraki Y: Expression of cartilage-specific functional matrix chondromodulin-I mRNA in rabbit growth plate chondrocytes and its responsiveness to growth stimuli in vitro. Biochem Biophys Res Commun 1998, 249(3):885-890.

doi:10.1186/1471-2121-12-34

Cite this article as: Miura et al:: Localization of chondromodulin-I at the

feto-maternal interface and its inhibitory actions on trophoblast

invasion in vitro. BMC Cell Biology 2011 12:34.

\section{Submit your next manuscript to BioMed Central} and take full advantage of:

- Convenient online submission

- Thorough peer review

- No space constraints or color figure charges

- Immediate publication on acceptance

- Inclusion in PubMed, CAS, Scopus and Google Scholar

- Research which is freely available for redistribution

Submit your manuscript at www.biomedcentral.com/submit 